\title{
Fundamentos Pedagógicos para o Uso de Simulações e Laboratórios Virtuais no Ensino de Ciências
}

\section{A Pedagogical Basis for the Use of Simulations and Virtual Labs in Science Education}

\section{Helder de Figueiredo e Paula ${ }^{(0)}$ Brasil}

Como podemos interpretar possíveis contribuições dos aplicativos de computador que contêm animações, simulações e laboratórios virtuais a partir de uma perspectiva sócio-histórica do ensino e da aprendizagem? Como identificar as potencialidades e as limitações desses aplicativos? Com quais demandas os estudantes são confrontados durante o trabalho de interpretação de representações complexas por meio das quais fenômenos e modelos das ciências são apresentados nesses aplicativos? Quais critérios podem ser usados para distinguir animações, simulações e laboratórios virtuais? Como podemos usar aplicativos que contêm simulações e laboratórios virtuais em uma perspectiva de ensino por investigação e por que vale a pena seguir essa orientação? Essas questões são apresentadas e discutidas ao longo das várias seções que compõem este artigo e nas quais nós apresentamos e utilizamos um conjunto de referenciais teóricos cujo valor para o enfrentamento das questões nós procuramos sustentar. Como estratégia argumentativa, recorremos à análise de alguns aplicativos disponíveis em sites bastante conhecidos por professores e por pesquisadores que se dedicam ao ensino e à aprendizagem das ciências.

Palavras-chave: Ação mediada; Mediação pedagógica; Animações, simulações e laboratórios virtuais; Inscrições didáticas; Ensino de Ciências por Investigação.

How can we understand potential contributions of simulations and virtual labs that simulate natural phenomena from a socio-historical point of view about teaching and learning processes? How to identify the constraints and affordances of this kind of software? What do students need to do while interpreting complex representations usually imbedded in most simulations and virtual labs? Which criteria can be used to distinguish animations, simulations and virtual labs? Could we use simulations and virtual labs in Inquiry Based Teaching? Why should we do it? In this paper, we discuss such issues, by proposing a theoretical framework and conduct analyses of some simulations and virtual labs available at sites well known by science teachers in Brazil.

Keywords: Mediated Action; Pedagogical mediation; Simulations and virtual labs; Inscriptions; Inquiry based teaching. 


\section{Introdução}

Na virada do século atual, o uso de Tecnologias de Informação e Comunicação (TIC) no ensino de ciências mobilizou vários pesquisadores (ver, por exemplo, Medeiros \& Medeiros, 2002; Fiolhais \& Trindade, 2003; Araujo \& Veit, 2004). Isso porque, de acordo com Bayraktar (2002), desde a última década do século passado, a educação em ciências figurava entre as áreas nas quais o ensino assistido por computador era o mais difundido e efetivo. O desenvolvimento de aplicações das TIC para essa área da educação escolar está em pleno processo de crescimento, tal como demonstram trabalhos como os de Finkelstein et al. (2005), Winn et al.(2006), Ma e Nickerson (2006); Klahr, Triona e Williams (2007); Zacharia, Olympiou e Papaevripidou (2008); Zacharia e Olympiou (2011), Jaakkola, Nurmi e Veermans (2011). Esse fenômeno acompanha o crescimento do uso das TIC nas mais diversas atividades econômicas e manifestações culturais nas últimas décadas.

Neste artigo, não trataremos das TIC de maneira geral, mas de aplicativos com animações, simulações e laboratórios virtuais usados no ensino de ciências. Em um trabalho de revisão bem amplo, Scalise et al. (2011) analisaram trabalhos publicados entre 1993 a 2009 em busca de evidências oriundas da pesquisa que fossem capazes de: (a) justificar o uso desse tipo de aplicativo no ensino de ciências; (b) permitir escolhas racionais de aplicativos adequados para determinadas finalidades pedagógicas; e (c) propor princípios de design no sentido de aumentar as chances dos aplicativos contribuírem com a aprendizagem.

Em um artigo publicado pouco depois, Paula e Talim (2012) apresentaram uma revisão de pesquisas mais modesta, mas considerada suficiente para sustentar a tese de que não há sentido em realizar pesquisas para justificar o uso de animações, simulações e laboratórios virtuais. Para esses autores, pesquisas como essas, na melhor das hipóteses, poderiam constatar que certos aplicativos e metodologias de ensino produzem certos resultados para um público específico, em um contexto também específico. Sendo assim, no lugar dessa validação, as pesquisas deveriam explicitar os fundamentos pedagógicos que sustentam a escolha e o uso de animações, simulações e laboratórios virtuais em contextos educacionais específicos.

Com o constante surgimento de novos aplicativos, a área de pesquisa dedicada ao uso de TICs no ensino de ciências tem se mostrado dinâmica e datada temporalmente, visto que os cenários avaliados e os softwares utilizados têm mudado rapidamente. Apesar disso, cremos ser possível identificar questões mais gerais, cuja pertinência é mais perene, tais como: (a) como podemos interpretar as contribuições dos aplicativos de computador que contêm animações, simulações e laboratórios virtuais, a partir de uma perspectiva sócio-histórica do ensino e da aprendizagem? (b) como identificar as potencialidades e as limitações desses aplicativos? (c) com quais demandas os estudantes são confrontados durante o trabalho de interpretação de representações complexas por meio das quais fenômenos e modelos das ciências são apresentados nesses aplicativos? (d) que critérios podem ser usados para distinguir animações, simulações e laboratórios 
virtuais? (e) como podemos usar aplicativos que contêm simulações e laboratórios virtuais em uma perspectiva de ensino por investigação e por que vale a pena seguir essa orientação?

Cada uma dessas questões é enfrentada em uma seção específica deste artigo. As respostas que apresentamos foram elaboradas a partir de exemplos extraídos da nossa prática e dos referenciais teóricos que têm orientado o uso e a avaliação de animações, simulações e laboratórios virtuais em nosso ambiente de trabalho. Este artigo não traz dados oriundos de uma pesquisa empírica, mas também não é puramente teórico, no sentido de estar desligado de uma prática pedagógica situada e específica. Em Paula e Talim (2012), nós empreendemos um primeiro esforço de explicitação dos fundamentos pedagógicos para o uso desses tipos de aplicativos em sala de aula. Naquela ocasião, os conceitos de mediação, ação mediada e recursos mediacionais sustentaram uma interpretação da avaliação que seis turmas de estudantes fizeram sobre as contribuições de um laboratório virtual em um curso de introdução aos circuitos elétricos. Como esses conceitos são retomados aqui, este artigo pode ser concebido como uma continuação daquele trabalho, cuja leitura, por essa razão, recomendamos.

\section{Marco teórico geral para uma concepção de ensino e aprendizagem}

Nesta seção, situamos o papel das mediações na constituição da atividade humana e, desde esse ponto de vista, enfrentamos a seguinte questão: como podemos interpretar possíveis contribuições dos aplicativos de computador que contêm animações, simulações e laboratórios virtuais a partir de uma perspectiva sócio-histórica do ensino e da aprendizagem?

Cremos que, na educação escolar, qualquer recurso ou método deve ser avaliado a partir das concepções de ensino e de aprendizagem daqueles que pretendem utilizálos. Há muitos anos temos orientado nossas concepções de ensino e aprendizagem a partir de leituras contemporâneas da obra de Lev S. Vygostsky (1896-1934). Essa obra é conhecida por ter inspirado teorias para as quais o ensino e a aprendizagem são processos que compartilham, com toda e qualquer atividade humana, uma natureza sócio-histórica e sociocultural (Wertsch, 1985, 1998, 2007).

De acordo com essa concepção, a atividade humana é constituída por ações e, além disso, toda ação especificamente humana é, necessariamente, uma ação mediada por artefatos culturais que têm sua própria história. A esse respeito, julgamos necessário alertar o leitor que, às vezes, a participação de artefatos culturais em determinadas ações não é imediatamente evidente. Certas mediações são usadas em operações realizadas automática e inconscientemente. Nesses casos, não nos damos conta de que existem artefatos culturais que medeiam aquilo que fazemos. Vejamos um exemplo: se pedirmos a alguém razoavelmente bom em matemática para "multiplicar de cabeça" o número 3 pelo número 176, essa pessoa tende a realizar a operação sem ter consciência de que está utilizando uma mediação com uma longa história cultural. Mas que mediação seria essa? 
É possível identificá-la caso: (a) exijamos que aquele a quem demandamos o cálculo explicite o raciocínio por ele utilizado; (b) proibamos esse sujeito de utilizar o sistema de numeração indo-arábico, de manipular um ábaco ou de repetir com as mãos os movimentos que simulam essa manipulação. Nessas novas condições, é altamente provável que a pessoa solicitada a efetuar o cálculo não consiga realizar a operação. Desse exemplo podemos concluir que, em nossa cultura, a "ação mental" associada à multiplicação 3 x 176 é realizada com mediações bem específicas: um algoritmo matemático baseado no sistema de numeração indo-arábico ou a manipulação de um ábaco.

A capacidade de produzir e utilizar artefatos culturais de forma extensiva e intensiva nos distingue de outros animais. Essa capacidade é considerada, inclusive, um marco do surgimento de nossa espécie. Basicamente, as ações da nossa espécie são caracterizadas: (i) pelo desenvolvimento de "ferramentas psicológicas", tais como as representações e os conceitos que permitem aos humanos evocar objetos e eventos ausentes em um dado contexto e, assim, aprender com erros passados e planejar atividades futuras; (ii) pelo uso das "ferramentas psicológicas" para a produção contínua de novas ferramentas materiais, que ampliam nossa capacidade de transformar o mundo físico e de "controlar"1 diversos fenômenos naturais.

A capacidade de evocar objetos e eventos ausentes, por meio de representações, deu origem às mais diversas formas de expressão e comunicação. Com representações e conceitos que têm como base, por exemplo, a linguagem, os gestos ou os objetos e as imagens produzidos artificialmente, nós, seres humanos, nos tornamos seres conscientes e verdadeiros viajantes no espaço-tempo histórico. Tornamo-nos, enfim, capazes de resgatar o passado para prever acontecimentos futuros.

Ferramentas humanas, tanto materiais, quanto "psicológicas", são produções culturais que sofreram um longo desenvolvimento desde o surgimento da nossa espécie. Hoje, dispomos de uma enorme variedade de tecnologias, sistemas de representação e modos de comunicação com os quais criamos a atual sociedade da informação. Com o auxílio da figura 1, Engeströn (1987) nos ajuda a entender o papel mediador das ferramentas materiais e "psicológicas" no surgimento de todas as capacidades especificamente humanas, entre as quais estão incluídas o ensino explícito ou estruturado e a aprendizagem ativa, cuja promoção é a principal atribuição da instituição escolar.

Na figura 1, o triângulo sólido e em primeiro plano representa um estágio anterior à evolução da nossa espécie. Esse triângulo nos mostra que as espécies do gênero homo que nos antecederam já eram animais sociais: cada indivíduo interagia diretamente com o ambiente para garantir sua sobrevivência (lado superior horizontal do triângulo sólido), além de também interagir com o mesmo ambiente a partir da mediação de

1 As aspas sobre a palavra "controle" servem para nos lembrar de eventos que revelam quão pequena é a capacidade humana de controlar os fenômenos naturais. Um acontecimento pitoresco e muito conhecido é o caso do gás freon usado antigamente em geladeiras e sistemas de refrigeração. Durante mais de seis décadas, o freon foi considerado inofensivo e não reativo até descobrimos que ele e outros clorofluorcarbonos reagem com o ozônio e destroem esse gás que protege a Terra de raios UV nocivos provenientes do Sol. 
outros indivíduos de sua comunidade (ver, na figura 1, o vértice inferior do triângulo sólido).

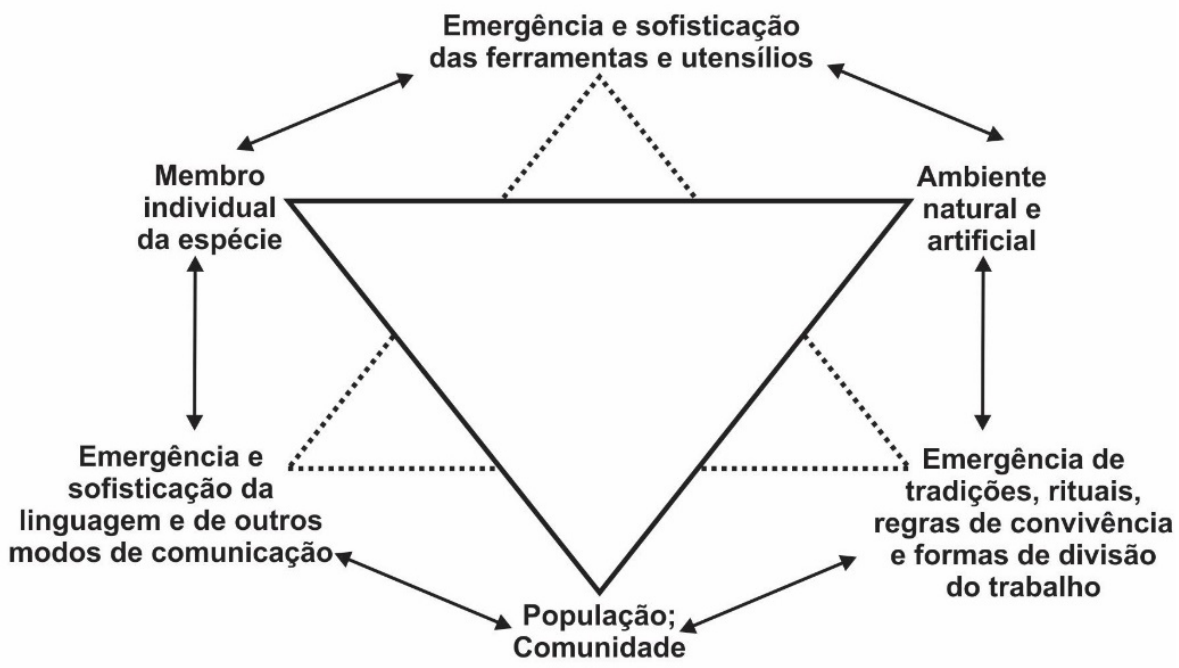

Figura 1. Uma concepção da gênese da atividade especificamente humana.

Fonte: tradução do diagrama original concebido por Engeströn (1987, p.63).

O triângulo feito com linhas tracejadas, e que está em segundo plano na figura 1, mostra a emergência das mediações a partir das quais nossa espécie se diferenciou, definitivamente, das espécies que a antecederam. $\mathrm{O}$ vértice superior do triângulo tracejado mostra que a relação entre cada membro individual da nossa espécie com o ambiente deixa de ser, predominantemente, direta. Ao invés disso, ela passa a ser uma relação essencialmente mediada por ferramentas e utensílios, cada vez mais sofisticados.

$O$ vértice lateral esquerdo do triângulo tracejado mostra que as formas primitivas de comunicação entre cada membro individual da espécie e a comunidade da qual ele fazia parte começaram a ser mediados por modos de comunicação cada vez mais sofisticados. Por sua vez, o vértice lateral direito do triângulo tracejado mostra que as relações entre a comunidade e o ambiente natural deixam de ser diretas e passam a contar com mediações que incluem rituais, tradições e formas de divisão do trabalho convencionalmente estabelecidas. Por fim, as setas duplas que ligam os elementos situados nos vértices dos triângulos sólido e tracejado mostram que cada um desses elementos modifica e é modificado pelos outros.

Por mais sofisticadas e específicas que sejam as atividades humanas hoje realizadas, todas seguem a mesma lógica de mediação representada no triângulo tracejado da figura 1. Por essa razão, podemos afirmar que o estudo da ação mediada e de suas propriedades nos permite entender os mais diferentes fenômenos sociais e culturais, por mais contemporâneos que sejam. Isso inclui, obviamente, a educação escolar, de modo geral, e o uso das simulações e laboratórios virtuais no ensino de ciências, em particular.

Partindo desse modo de compreender a atividade humana, podemos entender como novas mediações criam novas possibilidades de ação para os estudantes por meio das quais eles podem vir a dominar ou a se apropriar de certos conceitos e métodos 
das ciências. Algo similar se pode dizer em relação aos professores que também encontram em novas mediações, outras possibilidades de ação para compartilhar com os estudantes os significados desses mesmos conceitos e métodos. Essa é, portanto, a nossa resposta para a pergunta: o que ganhamos ao utilizar animações, simulações e laboratórios virtuais como mediadores das ações de professores e estudantes a partir de uma concepção sócio-histórica do ensino e da aprendizagem? Cremos que inserir o uso das TIC no estudo mais geral do papel dos recursos mediacionais na atividade humana pode fornecer uma sólida base teórica para planejar e avaliar o ensino de ciências. Esse enquadramento teórico guiará as respostas dadas, nas próximas seções deste artigo, às outras questões apresentadas na introdução.

Cremos, ainda, que a adoção de um referencial teórico como base para pesquisar ou avaliar a utilização de simulações e laboratórios virtuais no ensino de ciências pode representar um avanço em uma área na qual ainda prevalecem estudos dedicados à validação do uso de TICs mediante instrumentos do tipo pré-teste e pós teste, ou por meio da comparação de resultados educacionais obtidos em turmas que usaram, ou não, uma determinada Tecnologia de Informação e Comunicação. Nesse tipo de trabalho, nem os contextos educacionais nos quais as pesquisas foram realizadas, nem os fundamentos pedagógicos que orientaram o uso das TIC são adequadamente caracterizados.

\section{Potencialidades e limitações das animações, simulações e laboratórios virtuais no ensino das ciências}

Na seção anterior, apresentamos os marcos gerais da perspectiva sócio-histórica do ensino e da aprendizagem que utilizamos neste trabalho. A partir dessa perspectiva, defendemos a pertinência de considerar os aplicativos que contêm animações, simulações e laboratórios virtuais como mediadores das ações de professores e estudantes nas salas de aula de ciências. Werstch (1998) reúne muitas evidências e argumentos para sustentar a afirmação de que qualquer mediação possui, tanto potencialidades, quanto limitações. Essa afirmação dá sentido à segunda questão proposta na introdução deste artigo e que está orientada para a identificação de critérios para delimitar as potencialidades e limitações de animações, simulações e laboratórios virtuais. Para enfrentar essa questão, usaremos Werstch (1998) com o intuito de estabelecer uma distinção inicial entre os conceitos de recurso educacional e recurso mediacional.

O conceito de recurso mediacional é proposto por Werstch (1998, p.23-40), quando ele sugere a unificação dos conceitos de ferramentas materiais e "ferramentas psicológicas", que foram propostos, originalmente, por Vygotsky (1991). Para defender essa unificação, Werstch argumenta que: (i) o uso de ferramentas materiais não modifica apenas os objetos do mundo físico ou nossas ações sobre o mesmo, mas altera, também, a nós mesmos, ao interferir no fluxo e na estrutura de nosso funcionamento mental; (ii) "ferramentas psicológicas" também medeiam as ações nas quais as ferramentas materiais são utilizadas como mediações.

O conceito de recurso educacional nos remete aos grandes projetos ocidentais de 
ensino das ciências criados no contexto da guerra fria durante a década de 1960. Esses projetos concentraram seu investimento na produção de recursos educacionais e na prescrição de como os professores deveriam utilizá-los em sala de aula ${ }^{2}$. Por conseguinte, podemos dizer que, naquela época, a questão central das políticas públicas na área do ensino de ciências era: como os professores deveriam usar os recursos educacionais para que os alunos aprendessem? De acordo com Grandy e Duschl (2007), nas décadas seguintes, os estudantes passaram, progressivamente, a serem vistos como sujeitos de sua própria aprendizagem e daí surgiu uma concepção de educação em ciências para a qual a questão central passou a ser: o que os estudantes devem fazer para aprender?

O foco na ação dos estudantes transformou os recursos educacionais da escola e do professor em recursos que medeiam as ações dos estudantes ou, em outras palavras, os recursos educacionais foram transformados em recursos mediacionais. Essa mudança na função dos recursos usados no ensino e na aprendizagem das ciências não diminuiu a importância do professor, apenas promoveu uma alteração em seu papel. O professor, então, passou a ser considerado como o vicário de uma subcultura, que é a subcultura das ciências. Desde esse ponto de vista, a principal função do professor seria a de inserir os estudantes em práticas culturais de produção de conhecimento, de certa forma similares àquelas encontradas na atividade científica. Assim, ao se tornarem sujeitos dessas práticas, os estudantes realizariam ações mediadas com as quais eles poderiam vir a dominar certos conhecimentos e métodos das ciências.

Hoje, laboratórios virtuais constituem recursos mediacionais capazes de aumentar o protagonismo dos estudantes nas atividades de ensino e aprendizagem das ciências. Antigamente, por exemplo, alguns experimentos que desempenharam um papel crucial na história dos processos de produção e validação do conhecimento científico só podiam ser descritos para os estudantes por meio de imagens, vídeos e textos. Essa descrição ficava a cargo dos próprios professores ou dos textos didáticos por eles adotados. Questões ligadas ao custo, à segurança ou ao tempo necessário para a ocorrência de certos fenômenos, sempre impediram que diversos experimentos importantes fossem reproduzidos no ambiente escolar. Atualmente, porém, com o surgimento das TIC, existem aplicativos que criam, no computador, laboratórios virtuais semelhantes aos laboratórios reais. Esses laboratórios virtuais eliminam os problemas ligados à segurança ou ao tempo necessário para a realização de um experimento. Com esses aplicativos, os próprios estudantes conduzem experimentos cruciais ao entendimento dos conceitos, modelos e teorias das ciências, sendo também desafiados a interpretar os resultados desses experimentos.

O foco pedagógico nas ações dos estudantes como base da educação em ciências nos remete a uma análise dos recursos mediacionais que tornam possíveis essas ações. Dissemos, no parágrafo anterior, que novos recursos mediacionais, como aqueles proporcionados pelo desenvolvimento das TIC, criam novas possibilidades de ação para

2 Entre os projetos norte-americanos podemos citar o Biological Science Curriculum Study (BSCS), o Physical Science Study Committee (PSSC), o Project Harvard Physics, o ChemStudy e o Chemical Bond Approach (CBA). $\mathrm{Na}$ Inglaterra, os principais projetos foram concebidos pela Fundação Nuffield. 
os estudantes que os utilizam. Contudo, como Werstch (1998) argumenta, um recurso mediacional também introduz restrições às ações mediadas. Podemos exemplificar essa afirmação ao identificar algumas das possibilidades e limitações para a ação dos estudantes associadas a um aplicativo produzido pelo projeto Phet da Universidade do Colorado, que simula o Experimento de Rutherford ${ }^{3}$.

Começamos pela descrição da principal potencialidade desse aplicativo para as ações dos estudantes ou, mais especificamente, para os raciocínios que eles precisam realizar para compreender o Experimento de Rutherford. Uma potencialidade marcante é a rápida comparação que o aplicativo permite realizar entre os resultados obtidos por Rutherford e os resultados que "deveriam ter sido observados", caso a natureza realmente se comportasse como previa o modelo do átomo de Thomson. A janela aberta no computador pelo aplicativo apresenta duas abas superiores que se parecem com aquelas utilizadas nas antigas pastas para arquivar documentos em armários de escritório. A aba situada à esquerda dá aos estudantes acesso a animações que simulam os movimentos realizados pelas partículas alfa durante o experimento. A aba da direita mostra a previsão do modelo de Thomson acerca das trajetórias dessas partículas.

Uma das várias limitações que podem ser atribuídas ao aplicativo é a ausência de representações do aparato experimental utilizado na época e dos registros que Ernest Rutherford e sua equipe precisaram interpretar para imaginar como as partículas-alfa estavam se movimentando no interior do aparato. O julgamento da importância dessa limitação específica, dada aqui como exemplo, dependerá dos objetivos pedagógicos atribuídos ao curso de ciências no qual o aplicativo será utilizado. Será uma limitação certamente importante se um desses objetivos for oferecer oportunidades aos estudantes para compreender "como as ciências naturais funcionam", isto é, para que eles possam entender como os cientistas produzem as teorias a partir de interpretações dos experimentos por eles realizados. No caso do professor considerar importante esse objetivo, outros recursos para mediar a interação dos estudantes com o experimento em questão teriam de ser utilizados para sanar a limitação do aplicativo que, obviamente, poderia continuar a ser utilizado.

Esse exemplo nos permite sustentar uma recomendação importante que serve de resposta à pergunta: como identificar as potencialidades e as limitações de animações, simulações e laboratórios virtuais? O referencial teórico que apresentamos nesta seção sugere que o professor tome consciência dos objetivos pedagógicos que orientam o curso pelo qual ele é corresponsável, como condição para identificar as potencialidades e limitações de um determinado recurso que irá mediar as ações a serem realizadas pelos estudantes. Vale acrescentar que a tarefa de identificar as potencialidades e as limitações de um dado recurso mediacional só se torna possível mediante a comparação entre diferentes recursos. Afinal, como afirma Werstch (1998), as limitações de um recurso só são percebidas, a posteriori, quando novos recursos nos colocam diante de novas possibilidades para a ação.

$3 \mathrm{O}$ aplicativo possui tradução para o português e está disponível, gratuitamente, no link https://phet.colorado. edu/pt_BR/simulation/rutherford-scattering. 
Uma segunda sugestão importante oriunda do mesmo referencial teórico é a de que os professores estimulem os estudantes a utilizar diferentes recursos mediacionais, dado que as limitações de alguns desses recursos podem ser atenuadas pelas potencialidades de outros. Na literatura, encontramos trabalhos que corroboram essa recomendação ao apresentarem estudos de uso coordenado de diferentes recursos como forma de promover o ensino e a aprendizagem das ciências. Entre esses trabalhos podemos citar: Winn et al. (2006); Paula e Talim (2012); Dorneles, Araújo e Veit (2012); Heidemann, Araujo e Veit (2012); Pontone Jr. (2016). Este último trabalho merece destaque, pois mostra, de modo convincente, como o professor, sujeito da pesquisa, utiliza sua consciência das potencialidades e limitações dos vários recursos mediacionais que ele utiliza para combinar diferentes recursos orientados para os objetivos pedagógicos das aulas.

\section{Representações como pontes entre os mundos vividos e concebidos}

A ordem das questões apresentadas na introdução deste artigo segue a mesma linha de raciocínio que pautou a apresentação paulatina dos diversos autores que compõem nosso referencial teórico. Assim, nas seções anteriores, utilizamos Engeströn (1987) e Werstch (1998) para: (i) introduzir uma maneira de compreender a atividade humana a partir da qual animações, simulações e laboratórios virtuais podem ser entendidos como recursos mediacionais; (ii) distinguir os conceitos de recurso mediacional e educacional associando o primeiro a um foco na atividade dos estudantes como sujeitos dos processos de aprendizagem.

O foco na atividade dos estudantes como sujeitos da aprendizagem, por sua vez, nos leva à questão sobre as demandas com as quais eles são confrontados durante o trabalho de interpretação de representações complexas, normalmente encontradas nas animações, simulações e laboratórios virtuais. Na presente seção, damos um primeiro passo para enfrentar essa questão, ao caracterizarmos as representações usadas nas animações, simulações e laboratórios virtuais como pontes que ligam o mundo vivido pelos estudantes aos mundos concebidos pelas ciências (Roth, Ardenghi \& Han, 2005).

Já afirmamos aqui que as representações permitem aos seres humanos evocar objetos e eventos ausentes em um dado contexto. Uma disciplina importante que esclarece essa função das representações e o papel que elas cumprem na atividade humana é a Semiótica. O conceito central dessa disciplina é o de signo. A seguir, apresentamos uma definição de signo com o apoio da representação simplificada do átomo de Bohr apresentada na figura 2 . 




Figura 2. Modelo do átomo de Bohr.

Fonte: Ilustração feita pelo autor a partir de vasta iconografia disponível na internet.

De acordo com Peirce (1975) e Misak (2004), um signo pode ser concebido como o resultado de uma interação entre três elementos. Um desses elementos é um objeto material, uma palavra ou uma imagem recuperada da memória. Esse elemento exerce, na constituição do signo, o papel de representação e substitui o referente que é o segundo elemento do signo e também é aquilo que está sendo representado. No caso da figura 2, o disco central, em cujo interior vemos o sinal +, atua como uma representação, isto é, como o primeiro elemento de um signo. O objeto que essa representação substitui é o núcleo do átomo concebido por Bohr. O núcleo do átomo de Bohr é, portanto, o referente da representação situada no centro da figura 2.

Ocorre, porém, que precisa existir alguém (um estudante ou professor de ciências, por exemplo) ou algo (como um software que sirva à identificação e classificação de imagens) para realizar a operação de substituição do referente pela sua representação. Esse alguém ou algo que associa uma representação a um objeto por ela representado é o terceiro elemento do signo e recebe o nome de interpretante. Em síntese, um signo é o resultado da interação entre: (i) uma representação; (ii) um objeto ou um evento representado; (iii) algo ou alguém que irá associar a representação com o objeto ou o evento representado.

Dada essa definição de signo, podemos caracterizar a Semiótica como uma área do conhecimento que se ocupa de estudar os processos de produção, circulação e interpretação dos signos. O próprio Vygotsky (1999) deu importantes contribuições à Semiótica ao tratar a palavra como signo (Wertsch, 2007). A partir de Vygotsky, podemos atribuir aos signos uma dupla função: a mediação do pensamento individual de um dado sujeito sócio-histórico; e a comunicação entre sujeitos. A partir dessa perspectiva, mesmo quando estamos supostamente sozinhos, estaremos fazendo uso de signos, caso estejamos pensando em alguma coisa. Os signos que estruturam e constituem nosso pensamento foram apropriados a partir de nossa interação comunicativa com outros sujeitos, ao longo de uma vida compartilhada no seio de uma determinada cultura. Essa afirmação nos permite alterar a célebre frase "penso, logo existo", que foi pronunciada por René Descartes, para dizer algo do tipo 'penso por meio de signos e, por isso, existo como um sujeito sócio-histórico-cultural'. 
Uma estratégia para entender, preliminarmente, o que é a Semiótica consiste em apresentá-la como uma espécie de "linguística ampliada". Assim, enquanto a linguística se ocupa dos processos de produção, circulação e interpretação de signos verbais (palavras, expressões verbais, onomatopeias, etc.), a Semiótica se ocupa dos mesmos processos, mas lida com signos de todos os tipos, isto é, com sons, imagens, movimentos corporais, vestuário, interações com objetos, diagramas, fluxogramas, mapas, equações, etc.

A justificativa para a introdução da Semiótica como parte do referencial teórico reunido neste trabalho baseia-se na tese de que não devemos desprezar a dificuldade dos estudantes em interpretar os signos não-verbais por meio das quais as animações, as simulações e os laboratórios virtuais introduzem os estudantes nas formas de conceber e compreender os fenômenos que são típicas das ciências. Martins, Gouvea e Piccinini (2005) nos dão elementos para construir uma justificativa para essa tese quando mencionam a "ilusão da transparência da imagem". Com essa expressão, as autoras criticam a crença ingênua de que as imagens sempre comunicam de forma mais direta e objetiva do que as palavras. Essa crença está embutida na famosa afirmação de que "uma imagem vale mais do que mil palavras". Superar essa ilusão e adquirir conhecimentos úteis para a compreensão dos processos envolvidos na interpretação de imagens e outros signos não-verbais é uma das grandes contribuições da Semiótica para o ensino das ciências. Esse tipo de contribuição pode ser encontrado no livro escrito por Roth et al. (2005), que orienta a maioria das ideias apresentadas nesta seção,a partir de agora.

A obra desses autores está centrada no conceito de inscrição. Tal conceito foi inicialmente elaborado por Bruno Latour e seu círculo de colaboradores (Latour \& Woolgar, 1997; Latour, 2000). Uma inscrição é definida, inicialmente, como um conjunto organizado de medidas ou como um registro de aspectos específicos de um evento ou fenômeno. Esse registro sintético de informações e conhecimentos produzidos em um laboratório de pesquisa pode se apresentar em diferentes formas, tais como: (a) fotografias ou filmagens de um evento/fenômeno observado; (b) diagramas que criam imagens para destacar e apoiar certa descrição dos eventos/fenômenos; (c) medidas geradas por aparelhos inscritores (como o espectrofotômetro mencionado na figura 3, mais adiante); (d) gráficos que relacionam medidas realizadas diretamente por aparelhos ou cálculos de grandezas mais abstratas obtidas por via indireta; (e) equações que modelam, matematicamente, os eventos/fenômenos observados.

Aparelho inscritor é o termo usado por Latour e Woolgar (1987) para designar as máquinas e aparatos científicos que produzem as inscrições. Tanto os hardwares, quanto os softwares que permitem aos aparelhos inscritores registrar e organizar um conjunto de medidas foram concebidos a partir de teorias e equações das ciências. Embora o livro de Latour e Woolgar (1987) não faça menção específica à obra A Filosofia do Não (Bachelard, 1991), a noção de aparelhos inscritores é totalmente coerente com a noção de fenomenotécnica que Bachelard nos apresenta nessa obra, quando ele nos diz que:

Pode-se evocar um longo período em que o instrumento precede a sua teoria. $\mathrm{O}$ mesmo não acontece atualmente, nos domínios verdadeiramente ativos da ciência, em 
que a teoria precede o instrumento, de forma que o instrumento de física é uma teoria realizada, concretizada, de essência racional. (Bachelard, 1991, p. 25)

A partir de Bachelard (1991) podemos compreender porque Latour e seus colaboradores afirmam que os aparelhos inscritores permitem aos cientistas se apropriar de um gigantesco volume de conhecimentos produzidos em inúmeros outros domínios de pesquisa. Afinal, são nesses outros domínios que se originam muitos dos aparelhos inscritores usados em um laboratório. Isso justifica e dá sentido à afirmação de Latour e Woolgar (1997) segundo a qual a produção do conhecimento científico gira em torno da elaboração e da interpretação de inscrições. Para esses autores, as inscrições são, por assim dizer, a matéria-prima para a transformação de enunciados científicos em fatos atribuídos ao mundo dos fenômenos.

O uso compartilhado dos mesmos aparelhos inscritores no seio de uma determinada comunidade de pesquisadores explica como os procedimentos materiais que dão origem às inscrições são relegados ao domínio da "pura técnica" e deixados em segundo plano. Explica, também, como uma inscrição passa a ser confundida com o fenômeno de cuja investigação ela faz parte. Assim, a forte associação entre um fenômeno investigado e as inscrições produzidas nessa investigação faz com que uma inscrição particular, como um gráfico, por exemplo, possa vir a ser considerada como um avanço científico ou como uma evidência favorável ou contrária a uma dada teoria. Esse foi o caso, por exemplo, dos registros que Ernest Rutherford e sua equipe obtiveram ao estudar o espalhamento de partículas-alfa por uma fina folha de ouro. A inscrição que organizou esses registros constituiu a principal evidência a partir da qual a estrutura de um átomo pode ser comparada ao sistema solar.

As inscrições não devem ser compreendidas meramente como um recurso para o compartilhamento de informação, embora elas sejam efetivamente essenciais para que esse tipo de comunicação aconteça na comunidade científica. Antes até de cumprir essa finalidade, a produção de inscrições permite que os cientistas utilizem conceitos e teorias para criar uma interpretação estruturada e ordenada de um universo de acontecimentos que ocorrem nos laboratórios. Sem o uso de inscrições adequadas, tais acontecimentos não produziriam mais do que um amontoado de sensações desordenadas e desprovidas de significado. Sendo assim, as inscrições não apenas comunicam o conhecimento científico, mas medeiam o pensamento e o raciocínio dos cientistas no processo de construção desse conhecimento.

Nos processos de produção de conhecimentos típicos das ciências, são as inscrições que credenciam os mundos concebidos pelas teorias a funcionar como modelos capazes de simular os fenômenos do mundo vivido ou dos mundos produzidos nos laboratórios. Por outro lado, no caso do ensino das ciências, são as inscrições didáticas que medeiam os vínculos que os estudantes podem vir a estabelecer entre o mundo no qual eles vivem e os mundos concebidos pelas teorias das ciências. Em outras palavras, as inscrições didáticas são concebidas para apresentar aos estudantes os mundos ordenados e abstratos concebidos a partir das teorias das ciências, mas também para permitir que os 
estudantes dominem os conceitos e modelos das ciências para, por meio deles, modificar sua maneira de lidar com a realidade, com os outros e consigo mesmos.

Em síntese, as inscrições didáticas, tanto permitem o compartilhamento de conhecimentos entre o professor e os estudantes, quanto possibilitam a esses sujeitos uma compreensão estruturada e ordenada dos modelos e teorias das ciências. Esse é o caso, por exemplo, das inscrições didáticas apresentadas na figura 3, que permitem aos estudantes compreender como acontecem os processos de excitação e relaxação dos átomos de mercúrio existentes no interior de uma lâmpada fluorescente. Essa compreensão é vital, por exemplo, ao entendimento da função dos sais de fósforo que dão à lâmpada a aparência de um tubo branco e impedem que ela emita radiação ultravioleta, ao mesmo tempo, prejudicial ao nosso organismo e ineficaz em termos de iluminação ${ }^{4}$.

A figura 3 situa diferentes tipos de inscrições ao longo de um continuum que separa o mundo vivido pelos estudantes dos mundos concebidos no interior das ciências. Com exceção da equação que aparece no lado direito da figura, bem como da fotografia que aparece no lado esquerdo, todas as outras inscrições da figura 3 têm correspondência com aquelas encontradas na figura 4, apresentada e discutida na próxima seção deste artigo.

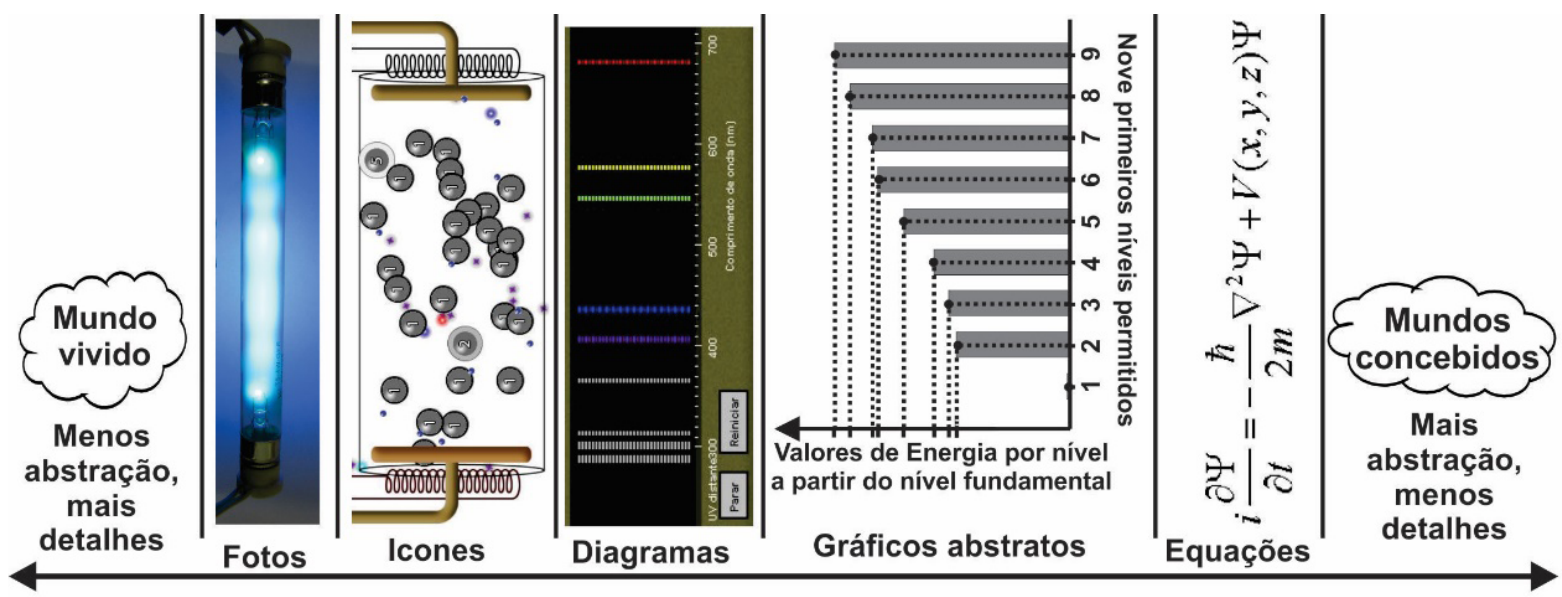

Figura 3. Continuum ontológico entre o mundo vivido e os mundos concebidos pelas ciências.

Fonte: Figura elaborada pelo autor a partir uma representação similar encontrada em Roth et al. (2005).

Da esquerda para a direita, na figura 3, nós encontramos as seguintes inscrições:

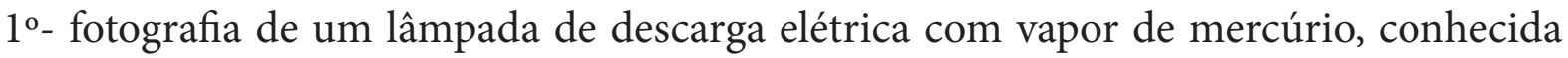
no mercado como lâmpada germicida; $2^{\circ}$ - ícones que representam os elementos que compõem esse tipo de lâmpada (eletrodos e filamentos nas extremidades de um tubo de vidro transparente no interior do qual encontramos átomos de mercúrio); $3^{\circ}$ - diagrama com a representação do espectro de emissão do átomo de mercúrio; $4^{\circ}$ - gráfico abstrato 4 Um exemplo de atividade no seio da qual essa compreensão adquire sentido e importância é apresentado em uma seção futura deste artigo. 
que compara os valores de energia para os nove primeiros níveis permitidos para os elétrons em um átomo de mercúrio; $5^{\circ}$ - equação geral com a qual a ciência pode prever e simular o comportamento do átomo de mercúrio, a partir de aproximações sucessivas que consideram as diversas interações entre os elétrons e o núcleo desse átomo.

No esquema mostrado na figura 3, quanto mais a esquerda estiver situada uma determinada inscrição, maior é a quantidade de informações contextuais que podemos obter a partir dela. Por isso, se tivesse maior tamanho e melhor definição, a fotografia mostrada no lado esquerdo da figura 3 permitir-nos-ia identificar até o fabricante da lâmpada de vapor de mercúrio usada para a geração dessa imagem. Deslocando nossos olhos imediatamente para o lado, encontramos uma ilustração feita com ícones que já não nos fornecem informações contextuais.

O espectro de emissão do átomo de mercúrio-que aparece classificado como um diagrama na figura 3 - pode ser produzido por um aparelho concreto (o espectrofotômetro ${ }^{5}$ ), que poderia ser manipulado por estudantes em laboratórios didáticos bem equipados. Nesse sentido, o espectrofotômetro poderia fazer parte do mundo vivido por esses sujeitos. Ainda assim, o espectro que compõe a figura 3 está mais próximo dos mundos concebidos pelas ciências do que a representação icônica da lâmpada e dos átomos de mercúrio nela contidos, presente na mesma figura. Isso porque, como nos disse Bachelard (1991), existe uma teoria que precede o espectrofotômetro, de forma que esse aparelho pode ser concebido como uma teoria realizada, concretizada, de essência racional. Tanto é verdade, que a imagem do espectro que compõem o diagrama da figura 3 não foi produzido por um espectrofotômetro real, mas por um algoritmo matemático que constitui o aplicativo Lâmpadas de neônio e outras lâmpadas de descarga ${ }^{6}$ que mencionamos, novamente, na próxima seção deste artigo.

O gráfico mostrado à direita do espectro do átomo de mercúrio na figura 3 é mais abstrato do que todas as outras inscrições encontradas à sua esquerda. Esse gráfico identifica os valores dos nove primeiros níveis de energia permitidos para o átomo de mercúrio. A diferença entre dois níveis específicos está relacionada a cada uma das linhas que compõem o espectro. Tal relação é dada pela equação de Planck $\Delta \mathrm{E}=\mathrm{h} . \lambda / \mathrm{C}$, na qual h e $\mathrm{C}$ são constantes universais da Física, $\Delta \mathrm{E}$ é a diferença de energia entre dois níveis permitidos e a letra grega $\lambda$ identifica cada comprimento de onda registrado no espectro.

$\mathrm{Na}$ extremidade direita da figura 3, encontramos a mais abstrata de todas as inscrições que a constituem. Trata-se da forma geral da equação de Schrödinger. Essa equação permite prever e simular as mudanças no estado quântico de um sistema físico, ao longo do tempo. Ela tem uma solução exata para objetos e eventos mais simples, tais como o átomo de hidrogênio, mas com ela também podemos obter soluções aproximadas para objetos e eventos mais complexos. Por isso, além do átomo de mercúrio, ao qual as várias inscrições da figura 3 fazem referência, a equação de Schrödinger se aplica a uma

5 Atualmente, o espectrofotômetro é um aparelho digital constituído por um hardware e por um software que realiza uma análise da intensidade e dos comprimentos de onda das radiações emitidas por um átomo. 6 Disponível em https://phet.colorado.edu/pt_BR/simulation/discharge-lamps, acesso em 01/08/2016. 
infinidade de outras situações, pois é capaz de simular o comportamento de moléculas e até mesmo de sistemas macroscópicos. Assim, a equação não nos remete a informações contextuais específicas que identificam um objeto, um evento, um fenômeno ou uma situação particular: seu campo de validade é simplesmente gigantesco!

Ao interpretarmos dessa maneira a figura 3, podemos concluir que o aumento no grau de abstração de uma inscrição tem como consequência uma redução da quantidade de informações contextuais específicas que ligam a inscrição a um contexto particular. Por outro lado, o aumento no grau de abstração permite que uma inscrição tenha referentes associados auma grande quantidade de diferentes situações. Em outras palavras, o aumento do grau de abstração implica em ganhos de generalidade e de abrangência, em termos das possibilidades de significação de uma determinada inscrição.

\section{Representações complexas formadas por várias inscrições didáticas}

Muitas representações que compõem as animações, as simulações e os laboratórios virtuais usados para o ensino e a aprendizagem das ciências são constituídas por imagens complexas, tais como a captura de tela do aplicativo Lâmpadas de neônio e outras lâmpadas de descarga, que aparece na figura 4. Nesta seção, discutimos o trabalho que um estudante necessita empreender para interpretar figuras como essa. Os professores são acostumados a lidar com essas representações, bem como a interagir com os objetos e eventos aos quais elas se referem. Por essas e por outras, alguns professores têm dificuldades em compreender os desafios enfrentados por muitos estudantes para interpretar esse tipo de representação complexa.

Representações complexas geralmente contêm várias inscrições didáticas que podem ser analisadas como camadas superpostas umas às outras ${ }^{7}$. Por um lado, representações em camadas como as mostradas na figura 4 permitem estabelecer percursos de leitura que vinculam o mundo vivido pelos estudantes e os mundos concebidos pelas ciências. Por outro, identificar as diferentes camadas presentes nesse tipo de representação complexa e relacionar essas camadas umas com as outras exige certo trabalho de interpretação que não deve ser desprezado.

As inscrições didáticas mostradas na figura 4 foram demarcadas pelos retângulos $\mathrm{A}, \mathrm{B}$ e $\mathrm{C}$, que nós introduzimos após realizar a captura de tela do aplicativo. Cada uma dessas três inscrições utiliza vários tipos de signos. Na inscrição didática A temos duas camadas sobrepostas. A primeira delas é constituída por ícones de elementos que constituem o hardware necessário ao funcionamento de uma lâmpada de descarga

7 O termo camada é utilizado nos softwares de tratamento de imagens. Assim, após fotografar uma pessoa em pé, nós podemos usar um software para decompor a fotografia em duas camadas: uma delas contendo a imagem do corpo da pessoa e a outra contendo todo o cenário situado ao redor. Os softwares de tratamento de imagens permitem não só separar essas duas camadas, mas criar novas imagens a partir delas. Por exemplo, a camada que contém a imagem da pessoa pode ser superposta a uma segunda camada contendo uma imagem de ondas em arrebentação em uma praia. Esse tipo de software permite incluir a imagem de uma prancha de surfe (terceira camada) abaixo dos pés da pessoa (primeira camada) e acima da crista de uma onda (segunda camada). A composição dessas três camadas irá sugerir que a pessoa fotografada em casa agora está surfando uma onda. 
elétrica: os eletrodos, os filamentos, o tubo transparente e fios condutores ligados a uma fonte de tensão. Os mesmos elementos dessa primeira camada podem ser observados em uma lâmpada de vapor de mercúrio, tal como aquela utilizada na atividade Investigando as lâmpadas fluorescentes, apresentada em uma seção posterior deste artigo. Contudo, na inscrição A, existe uma segunda camada composta por representações de entidades que pertencem ao mundo dos conceitos e teorias das ciências (mundo concebido): átomos de mercúrio, elétrons em movimento e fótons de luz (todos identificados na legenda situada no canto superior direito da figura 4).

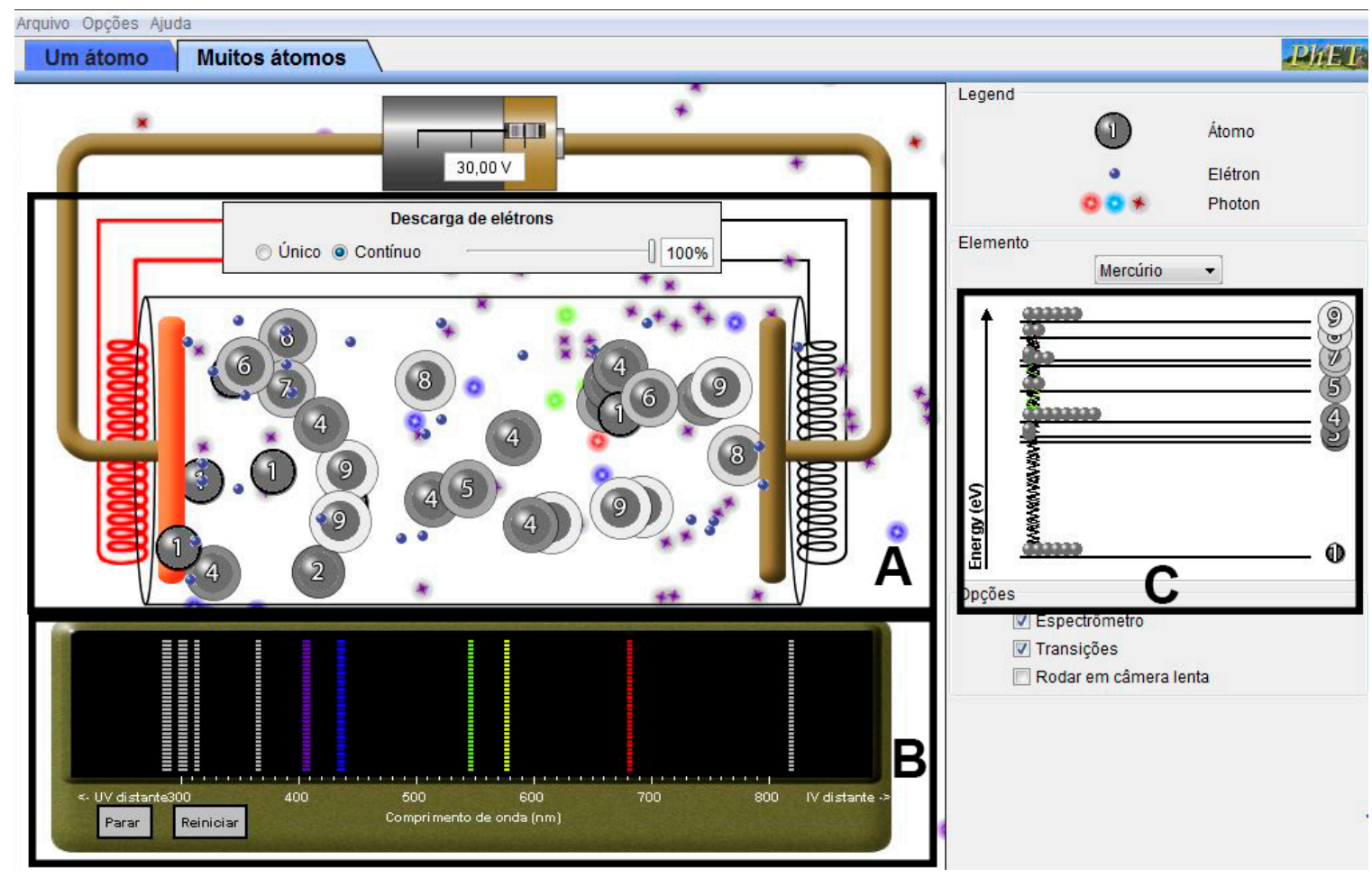

Figura 4. Captura de tela do aplicativo Lâmpadas de neônio e outras lâmpadas de descarga.

Fonte: imagem produzida pelo autor a partir da tela de um aplicativo disponível em https://phet. colorado.edu/pt_BR/simulation/discharge-lamps, acesso em 01/08/2016.

Na inscrição didática B, vemos uma camada composta por um conjunto de linhas coloridas iguais àquelas que podem ser observadas por meio de um espectroscópio caseiro. Mas, essa camada também contém linhas que não podem ser observadas a olho nu por estarem associadas às emissões de ultravioleta e infravermelho, ambas situadas fora do espectro do visível.

Apesar dos signos que compõem as inscrições didáticas A e B não serem exatamente iguais àquilo que um estudante observa ao lidar com uma lâmpada e com um espectroscópio encontrados no "mundo vivido no laboratório", elas muito provavelmente contribuem para que os estudantes compreendam a inscrição bem mais abstrata que aparece na área delimitada pelo retângulo $\mathrm{C}$ da figura 4.

Quando as opções do aplicativo Espectrômetro e Transições estão acionadas, 
surgem animações sincronizadas que produzem alterações na aparência dos signos contidos nas inscrições A, B e C. Como se pode observar no canto superior esquerdo da figura 4, o aplicativo oferece a possibilidade de observarmos essas animações sincronizadas para estudar o que acontece em um único átomo. Esse recurso é importante porque, como descrevemos a seguir, é muito grande o número de alterações sincronizadas que os estudantes precisam relacionar para compreender os processos de excitação e relaxamento que ocorrem nas lâmpadas de descarga elétrica. Quando múltiplos átomos de mercúrio aparecem na tela (ver figura 4) fica muito mais difícil relacionar as inscrições $\mathrm{A}, \mathrm{B}$ e $\mathrm{C}$.

A coordenação entre as animações apresentadas nas três inscrições destacadas na figura 4 é o principal recurso do aplicativo para vincular o mundo vivido pelos estudantes no laboratório ao mundo concebido pelas teorias das ciências. Na figura 3, as diferenças entre o valor da energia dos nove primeiros níveis permitidos para os elétrons do átomo de mercúrio são mostradas por meio de uma inscrição estática. Na inscrição C que compõe a figura 4, nós encontramos, basicamente, o mesmo tipo de informação. Todavia, na inscrição C, lidamos com uma representação dinâmica e sincronizada com alterações observáveis nas inscrições A e B.

$\mathrm{Na}$ inscrição didática $\mathrm{A}$, observamos várias mudanças na aparência das esferas maiores que representam átomos de mercúrio. Acompanhando atentamente as imagens colocadas em movimento pelo aplicativo, nós podemos ver as consequências da interação entre uma esfera/átomo e uma das bolinhas azuis que representam elétrons em movimento. Inicialmente, a interação provoca a elevação do número situado no meio das esferas/átomos e o surgimento de um anel externo ao seu redor. Instantes depois é possível observar três novas alterações nas imagens que compõem a inscrição A: (i) o anel externo em torno da esfera/átomo desaparece; (ii) o número situado no meio da esfera/átomo diminui; e (iii) ocorre a emissão de asteriscos difusos e coloridos que representam fótons de luz.

Como esclarece a legenda situada no canto superior direito da tela do aplicativo, as bolinhas de cor cinza representam elétrons de mercúrio. Junto ao surgimento do anel externo e à elevação do número impresso sobre os átomos representados na inscrição A, o estudante pode observar o salto entre níveis de energia dos elétrons representados na inscrição C.

As alterações sincronizadas na aparência das várias inscrições didáticas que compõem a tela do aplicativo servem para representar o processo de excitação do átomo de mercúrio. $\mathrm{O}$ movimento, em sentido inverso, no qual uma das bolinhas cinzas mostradas na inscrição $C$ retorna a um nível mais baixo de energia, coincide com a redução do número impresso sobre uma das esferas/átomos na inscrição A e com a emissão de um "fóton" que representa a liberação de um "pacote de energia" por essa esfera/átomo. Em outras palavras, essas animações sincronizadas representam o processo de relaxamento do átomo de mercúrio.

Cada vez que mudanças nas inscrições A e C indicam a emissão de um fóton, 
nós podemos observar um pequeno incremento na altura de uma das linhas situadas em posições específicas da escala horizontal que dispõe valores de comprimentos de onda na inscrição B. Paulatinamente, esses pequenos incrementos fazem surgir, em B, o espectro de emissão característico do átomo de mercúrio. A velocidade com que cada uma das linhas vai sendo formada serve para indicar quais transições entre níveis de energia permitidos para os elétrons de mercúrio são mais prováveis. As transições mais prováveis produzem linhas espectrais que crescem mais rapidamente e indicam em quais comprimentos de onda ocorre maior emissão de energia pelo átomo de mercúrio.

Além dessa sofisticada orquestração entre as alterações na aparência das inscrições contidas no aplicativo, o layout usado para dispor as inscrições no espaço da tela também nos remete a uma escolha dos designers aparentemente orientada para facilitar a interpretação de todo o processo. Esse layout atende a um princípio padrão utilizado em nossa cultura para a produção e interpretação da maioria das imagens ${ }^{8}$. De acordo com esse padrão, aquilo que resgata o conhecimento prévio do leitor ou que é mais facilmente interpretado por ele aparece antes. Esse é o padrão encontrado em textos escritos nas línguas ocidentais, nos quais o mais familiar é apresentado antes e se torna um elemento importante para a compreensão do novo ou do menos familiar.

Isso explica porque a inscrição A aparece na parte de cima e no lado esquerdo da tela do aplicativo. Afinal, essa inscrição é a que nos remete, mais diretamente, à lâmpada de descarga elétrica manipulada pelos estudantes no "mundo do laboratório". Abaixo da inscrição A, e situada no interior do mesmo grande quadro branco projetado na tela do aplicativo, nós encontramos a inscrição $B$, onde os estudantes podem observar o mesmo conjunto de linhas coloridas que eles observam no laboratório com a ajuda de um espectroscópio rústico. A posição da inscrição didática $\mathrm{C}$ sugere que os designers a concebem como mais abstrata, isto é, mais distante do mundo vivido pelos estudantes.

A análise que acabamos de apresentar permite vislumbrar uma parte do trabalho de interpretação da representação altamente complexa encontrada no aplicativo Lâmpadas de neônio e outras lâmpadas de descarga. O professor precisa estar ciente desse tipo de trabalho para atuar como mediador da interação entre os estudantes e esse tipo de aplicativo, caso isso seja necessário. A partir dessa análise, cremos ter fornecido elementos para ilustrar como identificar as demandas com as quais os estudantes são confrontados durante o trabalho de interpretação de representações complexas, normalmente encontradas nas animações, simulações e laboratórios virtuais.

Apesar de ter sido elaborada a partir de um exemplo específico, a análise que acabamos de apresentar foi construída com base em três importantes conceitos que podem ser aplicados em muitos outros contextos e situações: (i) o conceito semiótico de signo triádico, que pode ser entendido como uma relação entre uma representação, um referente e alguém/algo para quem a representação pode assumir o lugar do referente; (ii) o conceito semiótico de layout que é interpretado como um modo de comunicação

8 Essa e outras contribuições importantes para compreendermos os processos envolvidos na produção e interpretação de imagens podem ser encontradas na obra seminal de Kress e van Leeuwen (2006), que se tornou uma referência para o uso da Semiótica Social em pesquisas sobre a comunicação humana. 
pela Semiótica Social (Kress \& van Leeuwen, 2006; Kress, 2009); (iii) o conceito antropológico e epistemológico de inscrição que foi definida, inicialmente, como um conjunto organizado de medidas ou um registro de aspectos específicos de um evento ou fenômeno. Nesse último caso, para além dessa definição inicial, as inscrições foram, posteriormente, situadas em um continuum ontológico, que separa o mundo vivido pelos estudantes dos mundos concebidos pelas ciências.

\section{Diferenças entre animações, simulações e laboratórios virtuais}

Nas duas seções anteriores, apresentamos conceitos e ideias para identificar demandas com as quais os/as estudantes são confrontados durante a interpretação de representações complexas que compõem aplicativos com animações, simulações e laboratórios virtuais. Ocorre, porém, que esses três tipos de aplicativos têm características diferentes e, por essa razão, consideramos importante aprender a distingui-los. Nesta seção, nós enfrentamos essa questão na busca de critérios que possam ajudar professores a escolher qual é o tipo de aplicativo circunstancialmente mais adequado a um dado objetivo pedagógico.

O primeiro critério que propomos para distinguir animações, simulações e laboratórios virtuais diz respeito ao grau de interatividade entre o estudante e o aplicativo. No caso das animações, a interatividade é praticamente zero. O professor ou o próprio estudante iniciam a animação e, a partir de então, ficam limitados a assistir a uma sucessão de imagens em movimento que representam: (i) entidades e processos concebidos por um modelo científico; (ii) objetos e eventos que compõem um fenômeno natural; (iii) elementos que compõem a estrutura e o funcionamento de uma máquina ou aparato tecnológico. Assim, temos desde animações que mostram os processos atribuídos a sistemas ou entidades muito abstratas, como é o caso de um átomo, até animações de eventos que envolvem objetos bastante concretos, como o motor de combustão de um automóvel.

No caso das simulações, o grau de interatividade entre o estudante e o aplicativo não é zero como nas animações, e pode oscilar entre baixo, médio e alto. Isso porque, nas simulações, existem variáveis que o estudante pode alterar e cuja alteração permite a observação de diferentes comportamentos dos objetos ou materiais representados na tela do aplicativo. Quanto maior o número de variáveis que podem ser manipuladas pelos estudantes e quanto mais complexas forem as interações entre essas variáveis, maior será o grau de interatividade entre o estudante e a simulação.

Nos laboratórios virtuais, o grau de interatividade entre o estudante e o aplicativo varia entre médio e alto. Esse tipo de aplicativo permite a realização de experimentos muito similares àqueles que podem ser realizados em um laboratório real. Nesse caso, quanto mais complexos forem os experimentos, maior será o grau de interatividade proporcionado pelo aplicativo.

O segundo critério que propomos para distinguir animações, simulações e laboratórios virtuais está baseado no tipo de informações produzidas pelo aplicativo. 
Tipicamente, os laboratórios virtuais permitem a realização de medidas. Tais medidas são o resultado da interação do estudante com os objetos e equipamentos representados na tela do aplicativo. As simulações podem apresentar informações quantitativas, mas essa não é uma característica predominante nesse tipo de aplicativo. Por fim, nas animações, o estudante tem acesso ao mesmo tipo de informações que caracterizam as descrições ou as narrativas. Assim, as animações podem até fornecer informações quantitativas, mas essas informações não surgem a partir de medidas provenientes da interação do estudante com o aplicativo.

O terceiro critério que propomos para distinguir animações, simulações e laboratórios virtuais está baseado no tipo de representações predominantemente encontradas no aplicativo, bem como no tipo de referentes associados a essas representações. Esse critério distingue as simulações dos laboratórios virtuais, mas não incide sobre as animações. Afinal, nas animações, como dissemos anteriormente, podemos encontrar representações de, praticamente, tudo o que é de interesse para as ciências: modelos científicos, fenômenos naturais e máquinas ou aparatos tecnológicos.

No caso dos laboratórios virtuais predominam representações de objetos e eventos que pertencem ao mundo vivido e, mais especificamente, ao "mundo do laboratório". Nesse caso, encontramos muitos ícones que nos remetem aos equipamentos necessários à realização dos experimentos e que também são encontrados nos laboratórios reais. Contudo, diferentemente dos laboratórios reais, os laboratórios virtuais mesclam as representações que nos remetem aos objetos e eventos do mundo vivido com aquelas que se referem a entidades e processos pertencentes aos mundos concebidos pelas ciências. Esse é o caso, por exemplo, do laboratório virtual do Projeto Phet.Colorado denominado Kit de Construção de Circuito (DC). Com esse aplicativo, o estudante pode montar circuitos elétricos semelhantes àqueles que ele poderia montar em um laboratório de eletricidade básica. No entanto, além dos ícones de fios, baterias, lâmpadas e resistores, o estudante que utiliza o aplicativo também irá encontrar um signo cujo referente é abstrato: o fluxo de cargas elétricas no interior dos elementos do circuito.

Nas simulações predominam as representações de entidades e processos que constituem os modelos científicos ou, em outras palavras, que pertencem aos mundos concebidos pelas ciências. No caso dos laboratórios virtuais, o estudante modifica variáveis que alteram as representações exibidas na tela do aplicativo ao interagir com ícones de objetos e equipamentos. No caso das simulações, a interação do estudante se dá com entidades e processos cuja existência depende da adesão a uma teoria. Esse é o caso, por exemplo, da alteração da energia dos fótons que incidem sobre um átomo de Bohr, que nós encontramos no aplicativo BohrModel.swf, disponível no Banco Internacional de Objetos Educacionais do Ministério da Educação do Brasil ${ }^{9}$.

Note o leitor que um único critério isolado não nos permite diferenciar os três tipos de aplicativos acima mencionados. Isso nos obriga a utilizar os três critérios que propusemos nesta seção como um conjunto.

9 http://objetoseducacionais2.mec.gov.br/handle/mec/17906, acesso em 02/08/2016. 


\section{Simulações, Laboratórios Virtuais e Ensino por Investigação}

Ao retomar a introdução deste artigo, o leitor poderá notar que todas as questões com as quais nos comprometemos foram discutidas com exceção de uma que trata do uso de simulações e laboratórios virtuais em uma perspectiva de ensino por investigação. Seguindo o padrão adotado nas seções anteriores, nós discutimos essa questão a partir de um exemplo que dá sentido a novos elementos do referencial teórico que reunimos com o intuito de apresentar, neste artigo, alguns fundamentos pedagógicos para o uso de simulações e laboratórios virtuais no ensino de ciências.

A estruturação do ensino de ciências por meio da investigação (Inquiry Based Teaching) e a aposta nas atividades investigativas como forma importante de aprendizagem (Inquiry Based Learning) começaram a ser difundidos nos EUA há décadas, mas continuam em voga ainda hoje. Contudo, como afirmam, tanto Grandy e Duschl (2005), quanto Anderson (2002), não há consenso na literatura acerca de como caracterizar ou definir o que é uma atividade investigativa. É por isso que as ideias encontradas nesta seção não foram reunidas com a expectativa de resgatar ou representar a diversidade de perspectivas a partir das quais o ensino por investigação tem sido tratado no campo da pesquisa e da educação em ciências.

Ao invés disso, apresentamos uma compreensão das características e da importância das atividades investigativas que emergiu da prática pedagógica que temos construído na escola onde trabalhamos. Em linhas gerais, essa compreensão está baseada na crença de que a apropriação do conhecimento científico pelos estudantes depende da criação de situações em que esse conhecimento possa ser aplicado e avaliado na solução de problemas. Essas situações podem ser criadas no contexto de atividades investigativas.

O dicionário Houaiss da língua portuguesa atribui três significados ao verbete investigação: um geral, um pertinente ao contexto policial e um que nos remete a um jargão jurídico. No detalhamento do significado geral, a palavra investigação é tomada como sinônimo de pesquisa e assim interpretada como um "estudo ou série de estudos, geralmente extenso e rigoroso, sobre algum tema, especialmente do campo científico e/ ou artístico" (Houaiss, 2009). Essa definição é usada como nosso ponto de partida.

No campo das ciências, o tema que dá origem a uma pesquisa ou investigação geralmente assume a forma de uma questão ou pergunta, cuja resposta não pode ser obtida mediante um rápido apelo à memória ou por meio de uma consulta rápida e direta a uma fonte de informação facilmente acessível (outras pessoas, livros, internet, etc.). A impossibilidade de obter uma resposta imediata à pergunta que dá origem a uma investigação é que dá sentido ao termo "série de estudos" ou ao adjetivo "geralmente extenso", que são mencionados na definição de investigação resgatada do dicionário Houaiss.

Por se tratar de uma atividade relativamente extensa, o ato de investigar implica investir tempo e energia na busca de uma resposta à pergunta que dá sentido à investigação. A extensão ou duração do processo de investigação, por sua vez, depende de fatores objetivos, tais como o tempo disponível para conduzir a investigação, tanto 
quanto de fatores subjetivos, como a sensação de satisfação ou insatisfação em relação à quantidade e à qualidade dos conhecimentos produzidos e das experiências vivenciadas ao longo do processo.

Obviamente, para que o investimento necessário a uma investigação seja empreendido, a pergunta que dá início ao processo deve "valer a pena". Assim, para que os estudantes se envolvam em uma atividade investigativa, eles devem ter interesse pela pergunta ou pelo problema que constitui o motivo da investigação. Na pior das hipóteses, os estudantes precisam, ao menos, considerar que é necessário responder à pergunta ou ao problema, por alguma razão.

Essas primeiras afirmações nos permitem introduzir nosso principal argumento a favor da importância das atividades investigativas para o ensino das ciências. É comum os conhecimentos das ciências serem apresentados aos estudantes com a omissão das perguntas que deram origem a esses conhecimentos. Essa prática é prejudicial não apenas à compreensão do conhecimento científico, mas da própria ciência enquanto atividade humana. Afinal, como afirma Bachelard:

O espírito científico proíbe que tenhamos opinião sobre questões que não compreendemos, sobre questões que não sabemos formular com clareza. Em primeiro lugar, é preciso saber formular problemas. E digam o que disserem, na vida científica os problemas não se formulam de modo espontâneo. É justamente esse sentido de problema que caracteriza o verdadeiro espírito científico. Para o espírito científico, todo conhecimento é resposta a uma pergunta. Se não há pergunta, não pode haver conhecimento científico. Nada é evidente. Nada é gratuito. Tudo é construído. (1996, p. 18)

Sendo assim, propor e vivenciar atividades investigativas junto aos estudantes pode contribuir para que eles aprendam as ideias das ciências, enquanto aprendem sobre as ciências, bem como aprendem a "fazer ciências" (Hodson, 1992). Se aceitarmos o modo como Bachelard (1996) caracteriza a atividade científica, temos de admitir que a primeira e mais importante fase de uma investigação é a problematização ou a construção do problema. Afinal, a pergunta ou o problema formulado irá instigar e orientar o trabalho dos estudantes ao longo de todo o processo. Por essa razão, nas situações em que a situação-problema é apresentada pelo professor, é importante que ela seja reconhecida como problemática pelos estudantes. Independentemente da situaçãoproblema ou pergunta que dá origem a uma investigação ter sido proposta pelo professor ou pelos estudantes, podemos identificar duas ações gerais a serem realizadas nessa primeira etapa da atividade: (i) reconhecer uma dada situação como potencialmente problemática e identificar seus desafios; (ii) formular perguntas e identificar aspectos do tema que precisam ser melhor compreendidos.

O exemplo de problematização dado a seguir foi retirado de uma atividade denominada Investigando as lâmpadas fluorescentes, que tem sido utilizada, desde 2011, na escola onde trabalhamos. A pergunta apresentada aos estudantes no início desta atividade é: por que o governo brasileiro promoveu a substituição de lâmpadas 
incandescentes por lâmpadas fluorescentes a partir do início deste século e proibiu a comercialização das primeiras em 2016? Diante dessa pergunta, nós convidamos os estudantes a investigar a estrutura e o funcionamento dos dois tipos de lâmpada esclarecendo que essa ação fará com que eles venham a compreender por que uma delas é muito mais eficiente do que a outra.

No caso das lâmpadas fluorescentes, a investigação envolve o uso de um espectroscópio que permite aos estudantes comparar o espectro da luz proveniente de lâmpadas de mercúrio com e sem os sais de fósforo responsáveis pela fluorescência ${ }^{10}$. $\mathrm{Na}$ etapa seguinte, os estudantes exploram o aplicativo Lâmpadas de neônio e outras lâmpadas de descarga, que foi objeto de análise em uma seção anterior deste artigo. $\mathrm{Na}$ introdução dessa segunda etapa, eles encontram as seguintes questões: "Por que os átomos contidos em uma lâmpada de vapor de mercúrio emitem radiações com cores específicas? Por que o espectro da luz emitida pela lâmpada germicida é discreto, isto é, constituído por apenas algumas linhas ou comprimentos de onda?"

$\mathrm{Na}$ estrutura da atividade, cada nova etapa da investigação propõe uma exploração que é precedida de uma questão ou de um conjunto de questões cujo objetivo é dar sentido às ações e operações demandadas. Assim, na terceira exploração, um experimento gravado em vídeo apresenta características do vidro usado na fabricação das lâmpadas fluorescentes, após um questionamento acerca da segurança do uso desses dispositivos. O problema de segurança decorre de uma informação obtida na segunda exploração: a maior parte da energia emitida pelos átomos de mercúrio está situada na faixa do ultravioleta de alta frequência, uma radiação extremamente perigosa para a saúde humana!

Na quarta exploração, os estudantes simulam a fluorescência que ocorre no vidro das lâmpadas fluorescentes usando materiais seguros: lâminas de vidro cobertas com tinta comum e com tinta fluorescente de cor similar, além da radiação ultravioleta de baixa frequência proveniente de uma lâmpada de "luz negra". Essa exploração é precedida de uma problematização que retoma conhecimentos de explorações anteriores e que introduz novas questões: "A capacidade do vidro usado na fabricação das lâmpadas fluorescentes de impedir a propagação de radiação ultravioleta de alta frequência é uma importante medida de segurança. Mas, o que acontece com toda energia emitida pelos átomos de mercúrio na faixa do ultravioleta? Não seria possível aproveitar essa energia para a geração de luz visível?"

$\mathrm{Na}$ quinta exploração, os estudantes são confrontados com duas informações: (i) a fonte primária de radiação nas lâmpadas fluorescentes é a excitação de átomos de mercúrio; (ii) o descarte inadequado dessas lâmpadas contamina o ambiente com mercúrio, que é altamente prejudicial à saúde humana. Uma pergunta sobre políticas públicas voltadas para o descarte adequado de lâmpadas fluorescentes e outra sobre as práticas de descarte encontradas nas comunidades onde os estudantes vivem dá uma conotação política e ambiental a essa quinta exploração. O roteiro da atividade apresenta 10 Em Paula, Alves e Mateus (2011), o leitor encontrará as informações necessárias para a construção da luminária que contém as duas lâmpadas e do espectroscópio que são usados na atividade. 
um link para um vídeo que trata do tema e sugere que os estudantes façam incursões na Web, bem como uma pesquisa de campo em suas comunidades.

$\mathrm{Na}$ sexta exploração, os estudantes utilizam equipamentos para comparar, quantitativamente, a eficiência energética de lâmpadas incandescentes, fluorescentes e lâmpadas de LED. Desse modo, essa última exploração resgata a situação-problema que deu início a toda a investigação e permite aos estudantes avaliar seu grau de satisfação ou insatisfação em relação à quantidade e à qualidade dos conhecimentos produzidos e das experiências vivenciadas durante o processo.

O exemplo de atividade que acabamos de apresentar não é o de uma atividade investigativa prototípica, tal como caracterizada por Paula (2015). Ainda assim, acreditamos que ela pode figurar como sendo investigativa por dois motivos principais: (a) pela apresentação de questões que precedem e dão sentido às explorações propostas e pela caracterização das ações/operações sugeridas como meios para obtenção de respostas a essas questões; (b) pelo fato de que os estudantes da escola onde trabalhamos têm, efetivamente, se interessado pelas questões que estruturam a atividade e que isso tem os levado a se engajar nas ações e operações que a constituem.

Podem ser de cunho investigativo, mesmo as atividades nas quais a manipulação de uma simulação, de um laboratório virtual ou, ainda, de artefatos para experimentos, é realizada pelo professor. Para que não se configurem como meras demonstrações, basta que, em atividades desse tipo, os estudantes sejam estimulados a formular questões e fazer solicitações ou sugestões ao professor. Nesse caso, o professor provavelmente irá alterar as ações e operações que concebeu ao planejar a aula e transformará a atividade em um processo também dirigido pelas demandas e pelos interesses dos estudantes.

Em sua tese de doutorado, Pontone Jr. (2016) nos oferece diversos exemplos de como simulações e laboratórios virtuais podem ser utilizados em atividades de cunho mais investigativo.O professor, que é o sujeito da pesquisa de Pontone Jr. (2016), estabelece com os estudantes uma relação dialógica e a partir dela explora uma série de potencialidades das simulações e dos laboratórios virtuais que permitem a instauração de uma abordagem mais investigativa para o ensino e a aprendizagem da Física Escolar. Durante o uso do laboratório virtual que Pontone Jr. (2016) observou, o professor pausou os fenômenos representados pelo aplicativo e utilizou o recurso "avançar passo a passo", dando aos estudantes a oportunidade de elaborar questões e de fazer solicitações que o levaram a alterar parâmetros e variáveis relevantes para o fenômeno estudado. As simulações e laboratórios virtuais permitem a realização desse tipo de alteração com facilidade e rapidez.

Esse professor produziu os fenômenos, tanto com artefatos experimentais reais, quanto com o laboratório virtual e utilizou esse último para favorecer a visualização de processos inobserváveis nos experimentos feitos com objetos reais. Com essa estratégia, os conceitos e as teorias das ciências podem ser usados pelos estudantes como mediações para a interpretação dos fenômenos. Por fim, o professor transferiu aos estudantes, paulatinamente, a responsabilidade pelo uso dessas mediações, por meio de roteiros nos 
quais eles foram convidados a explorar outros fenômenos que podem ser produzidos com o mesmo laboratório virtual.

\section{Considerações finais}

Aplicativos contendo animações, simulações e laboratórios virtuais tem apresentado rápida evolução e as características desses aplicativos têm mudado bastante ao longo do tempo. Por isso, neste trabalho, nos propusemos a identificar algumas questões de caráter mais perene para orientar o uso, a avaliação e a pesquisa em torno de processos de ensino e de aprendizagem mediados por esse tipo de aplicativos. $\mathrm{Na}$ introdução, nós apresentamos cinco questões que, a nosso ver, exibem essa característica. De início, nos perguntamos sobre como podemos interpretar possíveis contribuições dos aplicativos de computador que contêm animações, simulações e laboratórios virtuais, a partir de uma perspectiva sócio-histórica do ensino e da aprendizagem. Para tratar dessa questão, nós resgatamos leituras contemporâneas da obra de Lev S. Vygostsky, a partir das quais procuramos sustentar o argumento de que considerar o uso desses aplicativos como parte do estudo mais geral dos recursos mediacionais que caracterizam a atividade tipicamente humana pode fornecer uma sólida base teórica para planejar e avaliar o ensino de ciências. Tanto em Paula e Talim (2012), quanto em Pontone Jr. (2016) encontramos evidências que apontam nesse sentido.

Na terceira seção, nós discutimos critérios para identificar potencialidades e limitações de aplicativos que contêm simulações e laboratórios virtuais e, em seguida, resgatamos a Semiótica para analisar possíveis demandas com as quais os estudantes são confrontados durante o trabalho de interpretação de representações complexas por meio das quais fenômenos e modelos das ciências são apresentados nesses aplicativos.

Também apresentamos critérios para distinguir animações, simulações e laboratórios virtuais e, com base neles, sugerimos que os professores considerem as diferenças entre esses aplicativos, antes de decidirem como utiliza-los em sala de aula. Por fim, nos perguntamos sobre o potencial desses recursos em uma perspectiva de ensino por investigação. Tendo caracterizado brevemente essa perspectiva e dado exemplos do potencial de simulações e laboratórios virtuais para realiza-la, cremos ter contribuído para que professores possam ampliar o protagonismo dos estudantes em sala de aula, bem como para que pesquisadores sejam estimulados a estudar, tanto os limites, quanto as potencialidades desses recursos em ambientes de ensino e aprendizagem orientados por uma abordagem investigativa.

Para terminar, gostaríamos de mencionar, brevemente, três revisões de literatura a partir das quais podemos situar melhor este texto, que agora chega a seu fim. A revisão realizada por Araújo e Veit (2004) teve como foco os estudos relativos ao uso de tecnologias computacionais no Ensino de Física. A base de artigos reunidos nessa revisão contemplou trabalhos publicados entre 1990 e 2003. Nesse período, esses autores consideraram a produção de pesquisas na área como bastante incipiente. A revisão realizada por Scalise et al. (2011), mencionada na introdução deste nosso 
artigo,contemplou 79 trabalhos publicados entre 1995 e 2009. Como conclusão, esses autores afirmaram que: (i) nenhuma pesquisa apresentava orientações fundamentadas para professores ou desenvolvedores de softwares; (ii) pouquíssimos trabalhos explicitavam fundamentos pedagógicos para o uso de aplicativos concebidos para o ensino e a aprendizagem de ciências. Conclusão semelhante a essa foi apresentada por Pontone Jr. (2016), cuja revisão também pode ser considerada abrangente, por contemplar muitos periódicos nacionais e estrangeiros e por se estender no período situado entre 2009 e 2014. Diante dessas revisões de literatura, que juntas abrangem um intervalo de tempo situado entre 1990 a 2014, bem como considerando que o foco deste artigo que agora finalizamos recai sobre o tema "fundamentos pedagógicos para o uso de simulações e laboratórios virtuais no ensino de ciências", acreditamos que nosso trabalho possa trazer algumas contribuições para a pesquisa na área a partir da integração das abordagens teóricas que o fundamentaram, bem como dos exemplos com os quais mostramos a pertinência e o potencial dessas abordagens.

\section{Agradecimentos}

À Fundação de Amparo à Pesquisa do Estado de Minas Gerais.

\section{Referências}

Anderson, R. D. (2002). Reforming Science Teaching: What Research says about Inquiry. Journal of Science Teacher Education, 13(1), 1-12.

Araujo, I. S., \& Veit, E. A. (2004). Uma revisão da literatura sobre estudos relativos a tecnologias computacionais no Ensino de Física. Revista Brasileira de Pesquisa em Educação em Ciências, 4(3), 5-18.

Bachelard, G. (1991). A Filosofia do Não. Trad. José J. M. Ramos. Lisboa, Editorial Presença.

Bachelard, G. (1996). A formação do espírito científico (1a ed.). Rio de Janeiro: Editora Contraponto.

Dorneles, P. F. T., Araujo, I. S., \& Veit, E. A. (2012). Integração entre atividades computacionais e experimentais como recurso instrucional no ensino de eletromagnetismo em física geral. Ciência \& Educação, 18(1), 99-122.

Engeström, Y. (1987). Learning by expanding: an activity-theoretical approach to development research. Finland: Orienta-konsultit.

Finkelstein, N. D., Adams, W. K., Keller, C. J., Kohl, P. B., Perkins, K. K., Podolefsky, N. S., ... LeMaster, R.(2005). When learning about the real world is better done virtually: a study of substituting computer simulations for laboratory equipment. Physical Review Special Topics - Physics Education Research, 1(1), 80-103. 
Fiolhais, C., \& Trindade, J. (2003). Física no computador: o computador como uma ferramenta no ensino e na aprendizagem das ciências físicas. Revista Brasileira de Ensino de Física, 25(3), 259-272.

Grandy, R., \& Duschl, R. (2007). Reconsidering the Character and Role of Inquiry in School Science: Analysis of a Conference. Science \& Education, 16(2),141-166.

Heidemann, L. A., Araujo, I. S., \& Veit, E. A. (2012). Ciclos de modelagem: uma proposta para integrar atividades baseadas em simulações computacionais e atividades experimentais no ensino de física. Caderno Brasileiro de Ensino de Física, 29(Especial 2), 965-1007.

Hodson, D. (1992). In search of a meaningful relationship: an exploration of some issues relating to integration in science and science education. International Journal of Science Education, 14(5), 541-562.

Houaiss, A. (2009). Dicionário Eletrônico da Língua Portuguesa. Versão monousuário 3.0. São Paulo, Editora Objetiva.

Jaakkola, T., Nurmi, S., \& Veermans, K. (2011). A comparison of students' conceptual understanding of electric circuits in simulation only and simulation laboratory contexts. Journal of Research in Science Teaching, 48(1), 71-93.

Klahr, D., Triona, L. M., \& Williams, C. (2007). Hands on what? The relative effectiveness of physical versus virtual materials in an engineering design project by middle school children. Journal of Research in Science Teaching, 44(1), 183-203.

Kress, G., \& van Leeuwen, T. (1996). Reading images: the grammar of visual design. London, Routledge.

Kress, G. (2009). What is mode? In C. Jewitt (Ed.). The Routledge Handbook of Multimodal Analysis (pp. 54-67), London, Routledge.

Latour, B., \& Woolgar, S. (1997). A vida de Laboratório: A produção dos Fatos Científicos. Rio de Janeiro, Dumará Distribuidora de Publicações Ltda.

Latour, B. (2000). Ciência em Ação. São Paulo, Editora Unesp.

MA, J., \& Nickerson, J. V. (2006). Hands-on, simulated, and remote laboratories: a comparative literature review. ACM Computing Surveys, 38(3) 1-24.

Martins, I., Gouvea, G., \& Piccinini, C. (2005). Aprendendo com imagens. Ciência e Cultura, 57(4), 38-40.

Medeiros, A., \& Medeiros, C. F. (2002). Possibilidades e limitações das simulações computacionais no ensino da Física. Revista Brasileira de Ensino de Física, 24(2), 77-86.

Misak, C. (2004). The Cambridge Companion to Peirce. Cambridge, UK: Cambridge University Press. 
Paula, H. F., Alves, E. G., \& Mateus, A. L. (2011). Quântica para Iniciantes: investigações e projetos. Belo Horizonte, Minas Gerais, Editora da UFMG.

Paula, H. F., \& Tatim, S. L. (2012). Uso coordenado de ambientes virtuais e outros recursos mediacionais no ensino de circuitos elétricos. Caderno Brasileiro de Ensino de Física. 29(Especial 1), 614-650.

Paula, H. F. (2015). As Tecnologias de Informação e Comunicação, o ensino e a aprendizagem de Ciências Naturais. In A. L. Mateus (Org.). Ensino de Química Mediado pelas TICs (pp. 169-196), Belo Horizonte, Minas Gerais, Editora da UFMG.

Peirce, C. S. (1975). Semiótica e Filosofia. São Paulo, Cultrix, Editora da Universidade de São Paulo.

Pontone JR., R. (2016). Simulações e laboratórios virtuais como recursosmediacionais multimodais nas ações de um professor de Física., 196 p. (Tese de Doutorado em Educação, Faculdade de Educação, Universidade Federal de Minas Gerais).

Roth, W. M., Ardenghi, L. P., \& Han, J. Y. (2005). Critical Graphicacy: Understanding Visual Representation. Netherlands, Springer.

Scalise, K., Timms, M., Moorjani, A., Clark, L., Holtermann, K., \& Irvin, P. S. (2011). Student learning in science simulations: design features that promote learning gains. Journal of Research in Science Teaching, 48(9), 1050-1078.

Vygotsky, L. S. (1991). A Formação Social da Mente. Trad. José Cipolla Neto. São Paulo, Martins Fontes (4a ed.).

Vygotsky, L. S. (1999). Pensamento e Linguagem. Trad. Jefferson Luiz Camargo. São Paulo, Martins Fontes, 2a tiragem da 2a ed. (original publicado em 1934).

Zacharia, C. Z., Olympiou, G., \& Papaevripidou, M. (2008). Effects of experimenting with Physical and virtual manipulatives on students' conceptual understanding in heat and temperature. Journal of Research in Science Teaching, 45(9), 1021-1035.

Zacharia, C. Z., \& Olympiou, G. (2011). Physical versus virtual manipulative experimentation in Physics learning. Learning and Instruction, 21(3), 317-331.

Wertsch, J. (1985).Vygotsky and the social formation of mind. USA: Harvard College.

Wertsch, J.(1998). Mind as action. New York, Oxford University Press.

Wertsch, J.(2007). Mediation. In H. Daniels, M. Cole, \& J. Wertsch (Orgs.). The Cambrigde Companion to Vygotsky (pp. 178-192). New York, Cambridge University Press.

Winn, W., Stahr, F., Sarason, C., Fruland, R., Oppenheimer, P., \& Lee, Y-L. (2006). Learning oceanography from a computer simulation compared with direct experience at sea. Journal of Research in Science Teaching, 43(1), 25-42. 
Helder de Figueiredo e Paula

(ㄷ) http://orcid.org/0000-0002-3860-8009 Universidade Federal de Minas Gerais Colégio Técnico Belo Horizonte, Brasil helder100@gmail.com

Submetido em 22 de Março 2015

Aceito em 10 de Setembro 2016

Publicado em 30 de Abril de 2017 